\title{
Simulation and Experimental Research on Cutting Force of Turning Titanium Alloy
}

\author{
Qingchun Zheng ${ }^{1,2}$, Cuilei Yang ${ }^{1,2}$, Shanqing Zhang ${ }^{1,2}$ and Yahui $\mathrm{Hu}^{1,2, a}$ \\ ${ }^{1}$ Tianjin Key Laboratory of the Design and Intelligent Control of the Advanced Mechatronical System, Tianjin 300384, China \\ ${ }^{2}$ Tianjin University of Technology, Tianjin 300384, China
}

\begin{abstract}
This paper mainly establishes a two-dimensional model about the YG8 carbide tool turning TC4 titanium alloy on the basis of ABAQUS. The cutting force of the simulation model was verified by the turning experiment, and the relationships of cutting force with cutting speed, feed rate and rake angle of cutting edge in the model were studied. A prediction model of main cutting force related to cutting speed, feed rate and rake angle was obtained by central composite experiment. Studies have shown that the difference between the cutting force acquired by simulation and by experiment was less than $10 \%$; in a certain range, the cutting force increased with the feed rate, the cutting force decreased with the increase of cutting speed and rake angle, and the influence of feed rate to cutting force was most significant.
\end{abstract}

Keywords: ABAQUS; TC4 titanium alloys; cutting force; central composite design

\section{Introduction}

Titanium alloys are widely used in the fields of aeronautics, astronautics, biomedical applications and chemical industry because of their high specific strength, strong corrosion resistance and nice heat resisting [1-3]. However, these materials are regarded as difficult to machine because of their high chemical reactivity and low thermal conductivity [4]. Cutting force is one of the important physical quantities in the studies of cutting process of titanium alloys, and the size and change of it have an effect on machining quality, tool wear and life, etc [5]. Therefore, accurate prediction of cutting force has a positive guiding significance to improve machining precision, prolong tool life in the cutting process for titanium alloy.

Finite element simulation of machining can be used as a supplementary to the physical experiment at a lower cost and offer predictions of process variables which are difficult to obtain by experiment [6]. In 1973, the finite element simulation technique was the first time applied to the field of Machining by B.E. Klamecki, and then, the method was widely used [7]. Ozden Isbilir etc [8] established a finite element model for drilling titanium alloy and analyzed the simulation results. Riaz Muhammad etc [9] constructed a finite element model of conventional and hybrid oblique turning processes of titanium alloy, and the cutting force and cutting temperature were analyzed. However, these studies were only qualitative research, did not obtain the prediction model.

Established a simulation model of turning titanium

a Corresponding author: Yahui Hu,yangcl_1989@126.com alloy in this paper on the basis of ABAQUS, it was verified by the turning experiment. And a prediction model of the cutting force related to cutting speed, feed rate and rake angle was obtained through researching the relationship between cutting force and cutting parameters, which provided a strong support for selecting reasonable parameters in the process of cutting titanium alloy.

\section{Establishment of simulation model based on ABAQUS}

\subsection{Geometric model}

The influence of cutting tool deformation and vibration to the simulation results were neglected in the finite element model, the cutting tool was assumed as a rigid body, and the whole simulation was two-dimensional analysis. Four node plane strain thermal coupling unit was used in meshing the workpiece and three node plane strain thermal coupling unit was used in meshing the tool. The meshes of cutting tool and workpiece were dense near the cutting area whereas others were relatively sparse. TC4 was used as the workpiece material, which was a kind of high strength titanium alloy. The material of the cutting tool in the simulation was YG8.

\subsection{Constitutive model}

Elastic-plastic flow is often taken place when workpiece material was under large strain and high strain rate during cutting process [10]. Considering to the influence of 
various factors on the flow stress of the workpiece material, it is the key to establish a reasonable flow stress model during the simulation analysis. The effect of strain hardening, strain rate hardening and softening temperature are organically contacted together by Johnson-Cook model [11]. Its mathematical expression can be expressed as following:

$$
\sigma=\left[A+B \varepsilon^{n}\right]\left[1+C \ln \left(\frac{\dot{\varepsilon}}{\varepsilon_{0}}\right)\right]\left[1-\left(\frac{T-T_{r}}{T_{m}-T_{r}}\right)^{m}\right]
$$

where $A, B, n, C$ and $m$ are the constants determined by the material itself, $T_{m}$ is melting point, $T_{r}$ is reference temperature, $\dot{\varepsilon}_{0}$ is reference strain rate. The five parameters of the Johnson-Cook material model are shown in Table 1.

Table 1, Constitutive model parameters of TC4

\begin{tabular}{|c|c|c|c|c|}
\hline $\mathrm{A}(\mathrm{Mpa})$ & $\mathrm{B}(\mathrm{Mpa})$ & $\mathrm{n}$ & $\mathrm{C}$ & $\mathrm{M}$ \\
\hline 910 & 780 & 0.47 & 0.035 & 1 \\
\hline
\end{tabular}

\subsection{Simulation model}

Figure. 1 shows the Simulation results. The cutting force value can be output in the Post-processing module of ABAQUS software. Changes of cutting force with cutting time were shown in Figure. 2 and the cutting force can be determined by the stable phase.

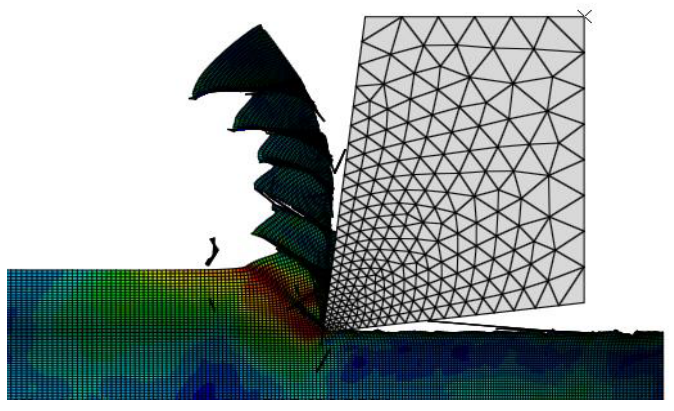

Figure.1 Simulation results

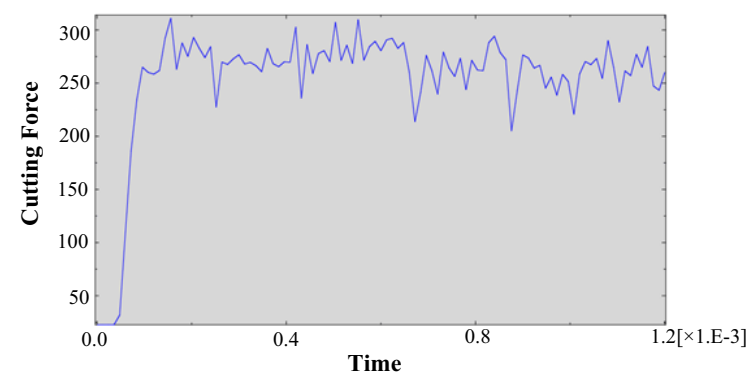

Figure.2 Curve of simulated cutting force

\section{Reliability verification of simulation model}

\subsection{Determination of cutting force in simulation and experiment}

In order to verify the reliability of the simulation model, the cutting forces simulated in different cutting speed were compared with the results of the turning experiments.

Figure. 3 shows a experiment of cutting titanium alloy which has been conducted on the CA6240 lathe, the data has been collected by Kistler9257B three-dimensional dynamometer and analyzed by DynoWare software. A curve of cutting force in the experiment is shown in Figure.4.

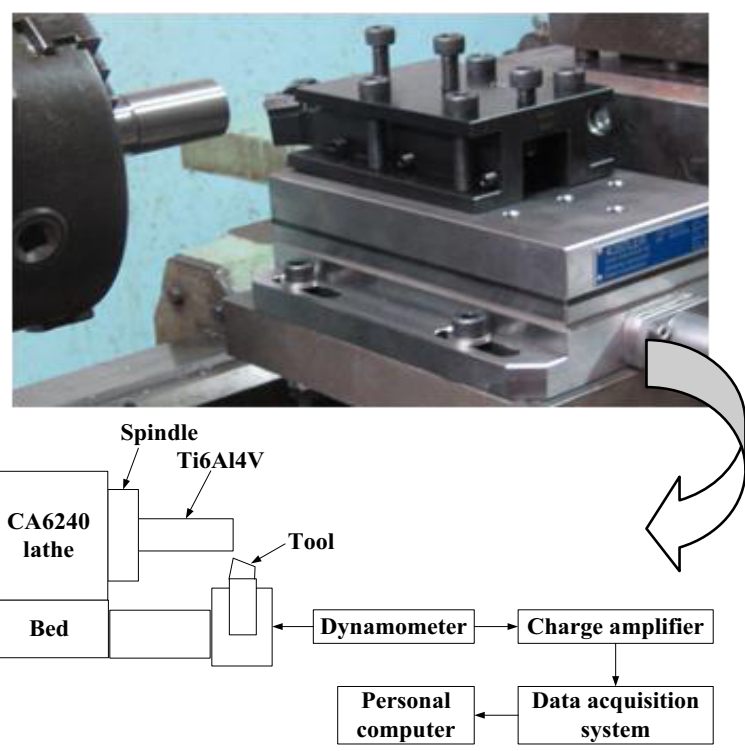

Figure.3 Cutting process of Titanium alloy

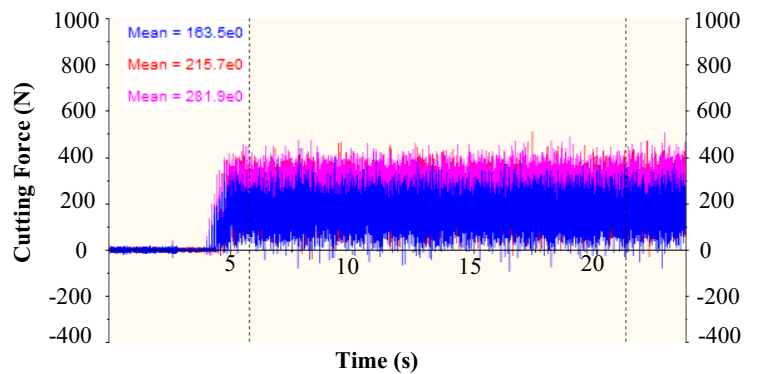

Figure.4 Cutting force curve of experiment

\subsection{Comparison between simulation and experimental results}

The finite element simulation and cutting experiments were carried out at the feed rate of $0.1 \mathrm{~mm} / \mathrm{r}$ and the cutting speeds of $30 \mathrm{~m} / \mathrm{min}, 50 \mathrm{~m} / \mathrm{min}, 70 \mathrm{~m} / \mathrm{min}, 90 \mathrm{~m} / \mathrm{min}$, and $110 \mathrm{~m} / \mathrm{min}$.

Figure. 5 shows that the values of main cutting force of the experiment and simulation are very approximate, the difference between the values of main cutting force is less than $10 \%$, and the cutting speeds show the little influence on the cutting force in the range of $30 \mathrm{~m} / \mathrm{min}$ to $110 \mathrm{~m} / \mathrm{min}$. Therefore, the simulation model of turning titanium alloy based on ABAQUS is reliable. 


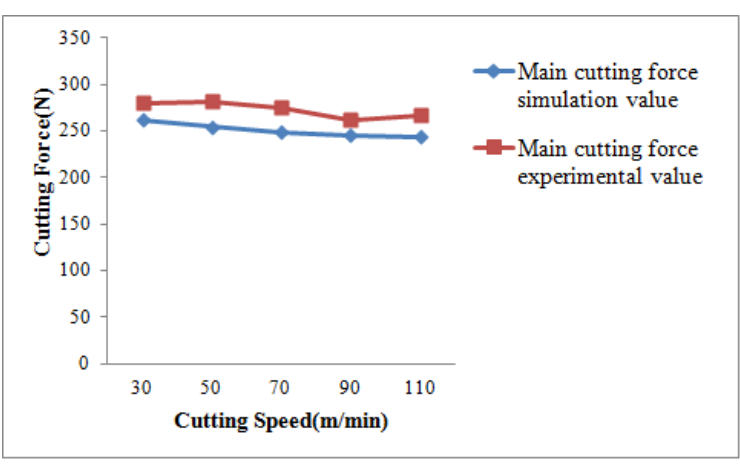

Figure.5 Comparison of main cutting forces between simulation and experiment

\section{Simulation and result analysis}

\subsection{Experiment design and results}

With the method of central composite design, the influence of cutting speed, feed rate and rake angle on the main cutting force were studied by using the simulation model. The experimental design scheme has shown in Table 2.

Table 2, Design of experimental

\begin{tabular}{|l|c|c|c|c|c|}
\hline $\begin{array}{l}\text { Parameter } \\
\text { level }\end{array}$ & $\begin{array}{c}-1.68 \\
18\end{array}$ & -1 & 0 & 1 & $\begin{array}{c}1.681 \\
8\end{array}$ \\
\hline $\begin{array}{l}\text { Cutting speed } \\
(\mathrm{m} / \mathrm{min})\end{array}$ & 39.77 & 50 & 65 & 80 & 90.23 \\
\hline $\begin{array}{l}\text { Feed rate } \\
(\mathrm{mm} / \mathrm{r})\end{array}$ & 0.02 & 0.05 & 0.1 & 1.5 & 0.18 \\
\hline Rake angle $\left(^{\circ}\right)$ & 5.64 & 7 & 9 & 11 & 12.36 \\
\hline
\end{tabular}

Experiments of the cutting have been carried out according to the arrangement of the simulation experiment. And the experimental results are shown in Table 3.

Table 3, Design and results of experiments

\begin{tabular}{|c|c|c|c|c|}
\hline No. & $\begin{array}{c}\text { Cutting } \\
\text { speed } \\
(\mathrm{m} / \mathrm{min})\end{array}$ & $\begin{array}{c}\text { Feed } \\
\text { rate } \\
(\mathrm{mm} / \mathrm{r})\end{array}$ & $\begin{array}{c}\text { Rake } \\
\text { angle }\left({ }^{\circ}\right)\end{array}$ & $\begin{array}{c}\text { Main } \\
\text { cutting } \\
\text { force }(\mathrm{N})\end{array}$ \\
\hline 1 & 50.00 & 0.05 & 7.00 & 143.48 \\
\hline 2 & 80.00 & 0.05 & 7.00 & 137.86 \\
\hline 3 & 50.00 & 0.15 & 7.00 & 366.22 \\
\hline 4 & 80.00 & 0.15 & 7.00 & 349.64 \\
\hline 5 & 50.00 & 0.05 & 11.00 & 133.51 \\
\hline 6 & 80.00 & 0.05 & 11.00 & 131.16 \\
\hline 7 & 50.00 & 0.15 & 11.00 & 351.48 \\
\hline 8 & 80.00 & 0.15 & 11.00 & 342.39 \\
\hline 9 & 39.77 & 0.10 & 9.00 & 239.56 \\
\hline 10 & 90.23 & 0.10 & 9.00 & 236.03 \\
\hline 11 & 65.00 & 0.02 & 9.00 & 69.94 \\
\hline 12 & 65.00 & 0.18 & 9.00 & 413.75 \\
\hline 13 & 65.00 & 0.10 & 5.64 & 257.37 \\
\hline
\end{tabular}

\begin{tabular}{|c|c|c|c|c|}
\hline 14 & 65.00 & 0.10 & 12.36 & 239.10 \\
\hline 15 & 65.00 & 0.10 & 9.00 & 243.63 \\
\hline 16 & 65.00 & 0.10 & 9.00 & 243.63 \\
\hline 17 & 65.00 & 0.10 & 9.00 & 243.63 \\
\hline 18 & 65.00 & 0.10 & 9.00 & 243.63 \\
\hline 19 & 65.00 & 0.10 & 9.00 & 243.63 \\
\hline 20 & 65.00 & 0.10 & 9.00 & 243.63 \\
\hline
\end{tabular}

According to the simulation results, the quadratic regression equation of cutting force is obtained:

$$
\begin{aligned}
& F_{x}=110.74-0.71 v+2429.37 f-11.24 \gamma_{0} \\
& -2.95 v f+0.045 v \gamma_{0}-6.65 f \gamma_{0}+0.0025 v^{2} \\
& -330.51 f^{2}-0.36 \gamma_{0}^{2}
\end{aligned}
$$

where $v$ is the cutting speed, $f$ is the feed rate, $\gamma_{0}$ is the rake angle. The scope of the cutting force prediction model is: $50 \mathrm{~m} / \mathrm{min} \leq \mathrm{v} \leq 80 \mathrm{~m} / \mathrm{min}, 0.05 \mathrm{~mm} / \mathrm{r} \leq \mathrm{f} \leq 0.15 \mathrm{~mm} / \mathrm{r}$, $7^{\circ} \leq \gamma_{0} \leq 11^{\circ}$.

\subsection{Model Testing}

Table 4 shows the results of the significance test between the regression equation and three parameters. It can be seen from table 4 that the quadratic regression model is significant and the feed rate, tool rake angle, cutting speed were ranked from high to low on the cutting force.

Table 4, Significance test

\begin{tabular}{|c|c|c|c|c|}
\hline Source & $\begin{array}{c}\text { Sum of } \\
\text { Square }\end{array}$ & $\begin{array}{c}\text { Mean } \\
\text { Square }\end{array}$ & F- value & P-value \\
\hline Model & 152900 & 16992.71 & 1467.4 & 0.0001 \\
\hline $\mathrm{v}$ & 232.88 & 232.88 & 20.11 & 0.0012 \\
\hline $\mathrm{f}$ & 152200 & 152200 & 13147 & 0.0001 \\
\hline$\gamma_{0}$ & 352.53 & 352.53 & 30.44 & 0.0003 \\
\hline
\end{tabular}

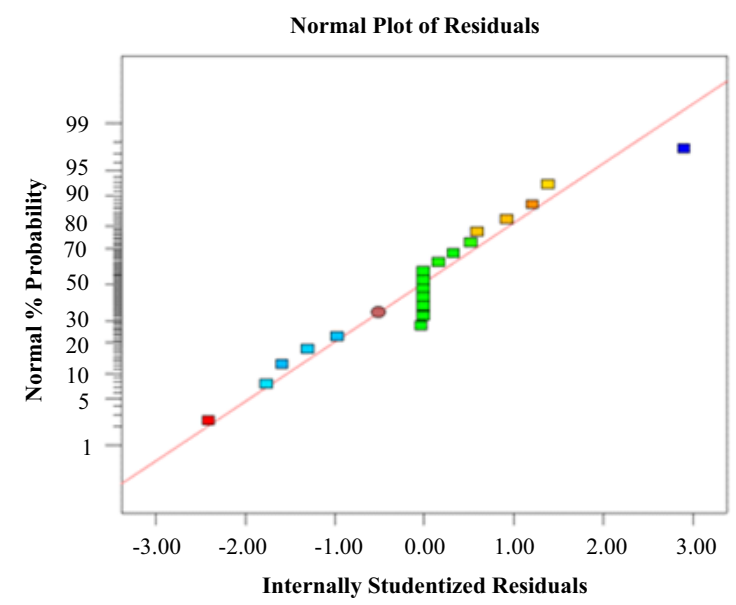

Figure.6 Residual analysis of cutting force

Figure.6 shows the residual figure, which can be obtained through residual analysis of the cutting force 
prediction model. From the diagram, it can be seen that the data points are distributed close to a straight line, which shows that the regression model close-fitting with the original data.

\subsection{Result analysis}

Figure. $7 \sim$ Figure. 9 shows the contour plots of cutting force and cutting parameters according to the main cutting force model.

The feed rate has strong influence on main cutting force. The reason is that the main cutting force increases significantly due to the force of friction between the chip and the cutting tool increases with the increase of feed rate. The main cutting force is slightly changed with the increase of cutting speed, which illustrates the cutting speed has slight effect on the main cutting force under the range of experiment. With the increase of rake angle, the shear angle in the primary deformation zone increases, the deformation coefficient reduces and the plastic deformation degree of the titanium alloy also reduces under the cutting process. Therefore, the main cutting force will decrease.

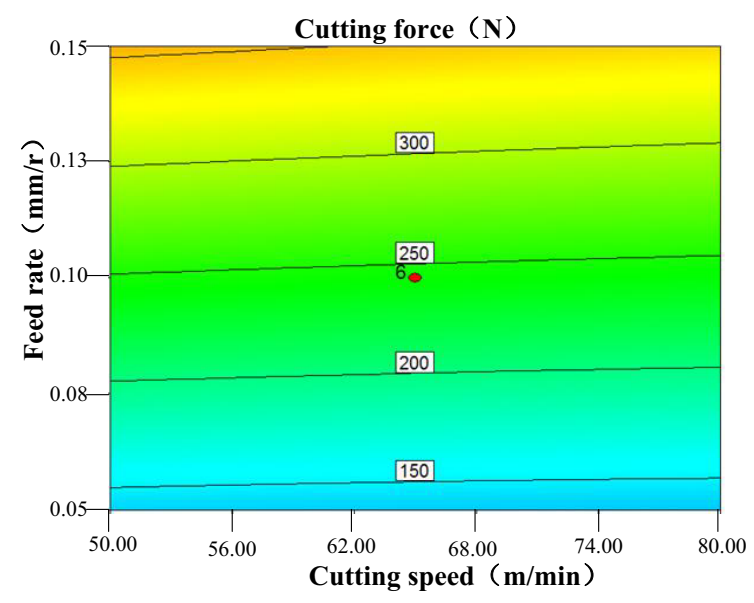

Figure.7 Influence of cutting speed and feed rate on cutting force $\left(\gamma_{0}=9^{\circ}\right)$

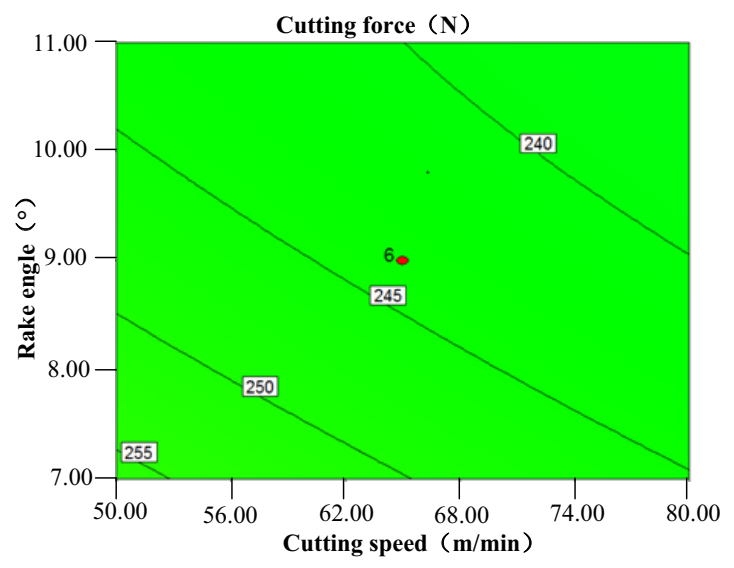

Figure.8 Influence of cutting speed and rake angle on cutting force $(\mathrm{f}=0.1 \mathrm{~mm} / \mathrm{r})$

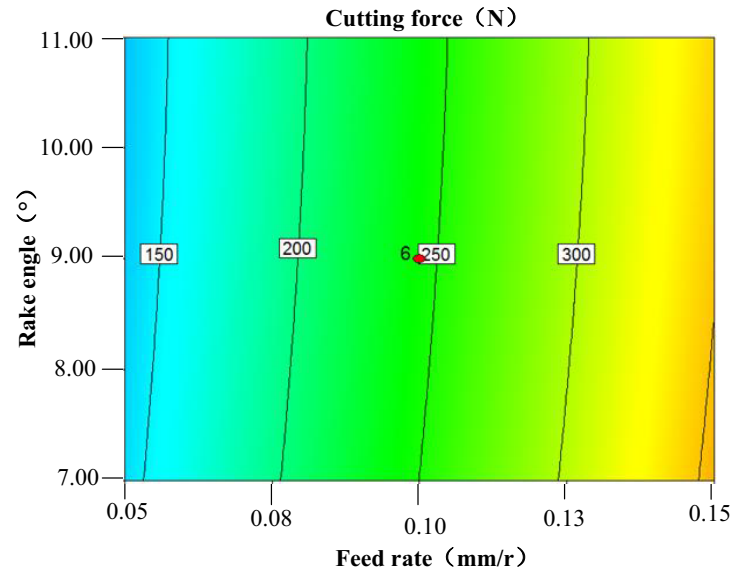

Figure.9 Influence of feed rate and rake angle on cutting force $(v=65 \mathrm{~m} / \mathrm{min})$

\section{Conclusions}

A simulation model of two-dimensional orthogonal on cutting TC4 was established in this paper. And the accuracy and reliability of the simulation model was verified by cutting experiments. A prediction model of cutting force related to cutting speed, feed rate and tool rake angle was established by using central composite design. The results obtained from above have been summarized as follows:

(1) The cutting force obtained by experiments is much close to the simulation results, which shows the simulation model is accurate and reliable.

(2) With the increase of cutting speed, the main cutting force slight decreases; with the increase of feed rate, the main cutting force increases; with the increase of rake angle, the main cutting force decreases.

(3) The influence of feed rate on cutting force is the most significant, followed by rake angle, and the cutting speed has the minimum effect on the cutting force.

\section{Acknowledgments}

The authors would like to acknowledge the financial support of the Natural Science Foundation of Tianjin (13JCYBJC17800), Natural Science Foundation of Tianjin (15JCZDJC32800) and National Training Programs of Innovation and Entrepreneurship for Undergraduates (201410060013).

\section{References}

1. Navneet Khanna, J.P.Davim. Design-of-experiments application in machining titanium alloys for aerospace structural components. Measurement, 61,280 (2015)

2. Jaroslav Fojt. Ti-6Al-4V alloy surface modification for medical applications. Applied Surface Science, 262,163 (2012)

3. Tang Bin, Xie Shao, et al. Crystal Plasticity Finite Element Simulations for Single Phase Titanium Alloys: Effect of Polycrystalline Aggregate Features 
on the Mechanical Response. Rare Metal Materials 4. Domenico Umbrello. Finite element simulation of conventional and high speed machining of Ti6Al4V alloy. Journal of Materials Processing Technology, 196,79 (2008)

5. Liansheng Gao, Yunxia Yuan, Hui Zhang. Modeling and experimental study on titanium alloy cutting force. Equipment manufacturing technology, 8,8 (2012)

6. Thanongsak Thepsonthi, Tu־grul Özel. 3-D finite element process simulation of micro-end milling Ti-6Al-4V titanium alloy: Experimental validations on chip flow and tool wear. Journal of Materials Processing Technology, 221,128 (2015)

7. Klamecki B E. Incipient Chip Formation in Metal Cutting: A Three Dimension Finite Element Analysis. University of Illinois at Urbana-Champaign (1973) and Engineering, 44,0267 (2015)

8. Ozden Isbilir, Elaheh Ghassemieh. Finite Element Analysis of Drilling of Titanium Alloy. Procedia Engineering, 10,1877 (2011)

9. Riaz Muhammad, Anish Roy, Vadim V. Silberschmidt. Finite Element Modelling of Conventional and Hybrid Oblique Turning Processes of Titanium Alloy. Procedia, CIRP 8,510 (2013)

10. Yugang Ye,Yan Yin. The establishment of a dynamic constitutive model for cutting of titanium alloy TC4 by finite element simulation. Ordnance Material Science and Engineering, 32,35 (2009)

11. Johnson G.R,Cook W.H. A constitutive model and date for metals subjected to large strains, high strain rates and high temperatures. Presented of the Seventh International Symposium on Ballistics, 541 (1983) 